\title{
Cobalt(II) supported on ethylenediamine-functionalized nanocellulose as an efficient catalyst for room temperature aerobic oxidation of alcohols
}

\author{
AHMAD SHAABANI*, SAJJAD KESHIPOUR, MONA HAMIDZAD \\ and MOZHDEH SEYYEDHAMZEH \\ Faculty of Chemistry, Shahid Beheshti University, G. C., P. O. Box 19396-4716, Tehran, Iran \\ e-mail: a-shaabani@sbu.ac.ir
}

MS received 18 June 2013; revised 22 September 2013; accepted 25 September 2013

\begin{abstract}
Ethylenediamine-functionalized nanocellulose complexed with cobalt(II) was found to be a highly efficient heterogeneous catalyst for the room temperature aerobic oxidation of various types of primary and secondary benzylic alcohols into their corresponding aldehydes and ketones, respectively. The catalyst showed no significant loss of efficiency after five reaction cycles.
\end{abstract}

Keywords. Heterogeneous catalyst; aerobic oxidation; alcohols; modified-nanocellulose; cobalt.

\section{Introduction}

Selective oxidation of alcohols to their corresponding carbonyl compounds is of significant importance in organic chemistry, both for fundamental research and industrial manufacturing. This transformation is traditionally carried out using stoichiometric quantities of inorganic oxidants, which are relatively expensive, highly toxic and environmentally polluting. ${ }^{1-3}$ Therefore, introducing green, selective and efficient aerobic oxidation systems for alcohols are of prime importance for both economic and environmental reasons. Numerous aerobic catalytic homogeneous oxidation approaches are reported for alcohols using $\mathrm{O}_{2}$ as oxidant, which are inexpensive and produce water as the sole product. ${ }^{4,5}$ Homogeneous catalysts increase activity, since alcohols and catalysts coexist in the same phase. However, homogeneous catalysts have drawbacks such as tedious catalyst separation and recycling, and pollution of the product with catalyst. Immobilization of homogeneous catalyst on solid supports not only simplifies reaction procedure and increases stability and recyclability of the catalyst, but it is also an important technique to render homogeneous systems heterogeneous. ${ }^{1-3,6}$ Therefore, the development of new heterogeneous catalytic systems based on reusable and biodegradable solid support for the aerobic oxidation of alcohols under ambient conditions should attract a great

*For correspondence deal of attention in both green chemistry and organic synthesis.

Many different materials have been employed to support in heterogeneous catalytic systems, such as mesoporous silica, ${ }^{7,8}$ activated carbon, ${ }^{9-11}$ (bio)polymer ${ }^{12,13}$ and biomass. ${ }^{14}$ With increasing concern about environmental pollution, the direction of science and technology has been shifting more towards eco-friendly, natural product resources and reusable catalysts. Thus, natural biopolymers are attractive candidates for such solid support catalysts. Among several reusable and heterogeneous supports, cellulose as an inexpensive and biodegradable natural polymer is one of the useful examples, that can be easily separated, reused and is not contaminated by the products. ${ }^{15,16}$ Cellulose whiskers, a name that refers to the needle-like structure of the crystallite, was separated from various sources such as wheat straw and tunic in. This nanostructured fibre has very high aspect ratio which gives exceptional characteristics to the nanofibre. ${ }^{17}$

Numerous examples of cellulose-supported organic transformations are reported in the literature. ${ }^{18-20}$ Herein, we wish to highlight a new catalytic system including $\mathrm{Co}(\mathrm{II})$ supported on ethylenediaminefunctionalized nanostructured cellulose (Co(II)EDANC) as an efficient and reusable catalyst for aerobic oxidation of various benzylalcohols. Our group's contributions to this field are linked to our broader interest in the development of aerobic oxidation reactions $^{21-23}$ and cellulose-supported catalysts. ${ }^{21,24-28} \mathrm{We}$ focus particularly on $\mathrm{Co}$ (II)-promoted oxidative transformations of alkyl arenes, alcohols, and silyl ethers. 


\section{Experimental}

\subsection{General}

All reagents were purchased from Aldrich or Merck and used without further purification. Cellulose nanocrystals was prepared as reported in the literature with a length between 200 and $400 \mathrm{~nm}$ and a width less than $10 \mathrm{~nm}$ in approximately. ${ }^{29}$ Products were analysed using a Varian 3900 GC. Thermogravimetric analysis (TGA) was carried out using STA 1500 instrument at

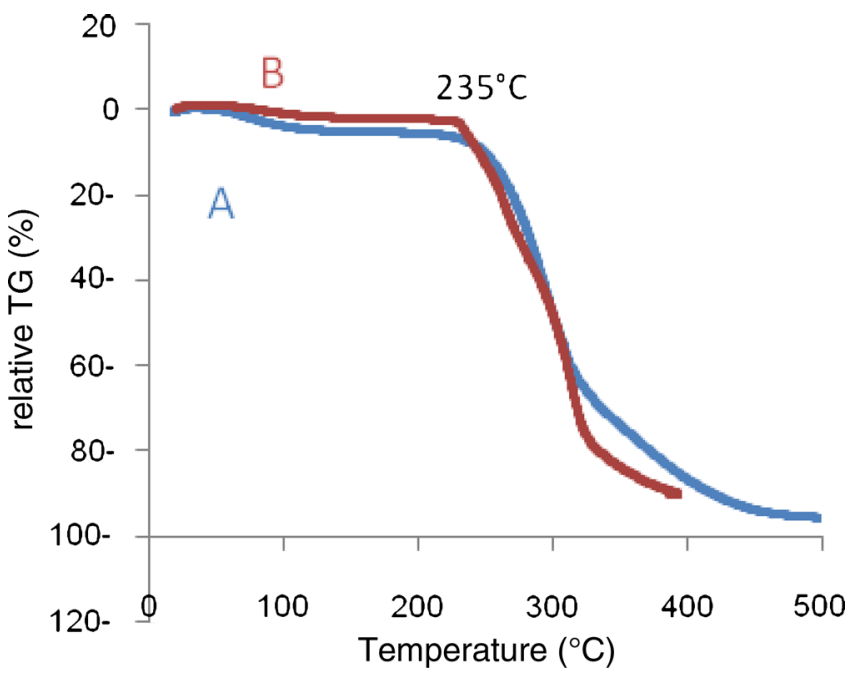

Figure 1. TGA spectra of Co(II)-EDANC (A) and recovered Co(II)-EDANC (B) in air. a heating rate of $10^{\circ} \mathrm{C} \mathrm{min}^{-1}$ in air. $\mathrm{Co}$ (II) determination was carried out on an FAAS (Shimadzu model AA680 atomic absorption spectrometer) with a Co hollow cathode lamp at $240.7 \mathrm{~nm}$, using an air-acetylene flame.

\subsection{Preparation of $C o(I I)-E D A N C$}

In a typical procedure, a mixture of nanocellulose $(2.00 \mathrm{~g})$ and $\mathrm{LiCl}(0.05 \mathrm{~g})$ in $21 \mathrm{~mL}$ of DMF was prepared. After $8 \mathrm{~h}$ stirring at room temperature, $8 \mathrm{mmol}$ tosylchloride and $0.10 \mathrm{~mL}$ triethylamine were added to the mixture, and stirring continued for $24 \mathrm{~h}$ at $8^{\circ} \mathrm{C}$ to afford cellulose tosylate (CT). Then, the mixture containing CT was treated with $9 \mathrm{~mL}$ water and $9.00 \mathrm{mmol}$ ethylenediamine. Instantly, temperature was raised to $100^{\circ} \mathrm{C}$ and stirring continued. After $16 \mathrm{~h}$, the mixture was cooled to room temperature and poured into $60 \mathrm{~mL}$ acetone. The polymer was filtrated and washed thrice with acetone. It was dried under vacuum at $60^{\circ} \mathrm{C}$ to afford ethylenediamine-functionalized nanocellulose (EDANC). Ethylenediamine content in the nanocellulose was calculated to be $0.06 \mathrm{mmol} / \mathrm{g}$, according to the nitrogen content in EDANC measured by $\mathrm{CHN}$ analysis. Then, $2.00 \mathrm{~g}$ EDANC was added to $10 \mathrm{~mL}$ solution of $\mathrm{CoCl}_{2}(4.00 \mathrm{mmol})$ in $\mathrm{H}_{2} \mathrm{O}$. The mixture was stirred at room temperature, after $24 \mathrm{~h}$, the mixture was filtered, and the residue washed successively with $\mathrm{CH}_{3} \mathrm{CN}(3 \times 5 \mathrm{~mL})$, and dried under vaccum at $80^{\circ} \mathrm{C}$ to give the dark polymeric cobalt(II) supported on ethylenediamine-functionalized nanocellulose ( $\mathrm{Co}$ (II)EDANC).

Table 1. Optimization of the reaction conditions for aerobic oxidation of alcohols.

\begin{tabular}{lcllc}
\hline Entry & $\begin{array}{c}\text { Amount of catalyst } \\
(\mathrm{Co}(\mathrm{II}) \text { content/mol\%) }\end{array}$ & Solvent & \multicolumn{1}{c}{$\begin{array}{c}\text { Base } \\
(\text { amount })\end{array}$} & $\begin{array}{c}\text { Yield } \\
(\%)^{\mathrm{a}}\end{array}$ \\
\hline 1 & 1.2 & $o$-xylene & $\mathrm{KOH}(0.5)$ & 51 \\
2 & 2.3 & $o$-xylene & $\mathrm{KOH}(0.5)$ & 84 \\
3 & 3.5 & $o$-xylene & $\mathrm{KOH}(0.5)$ & 95 \\
4 & 3.5 & $o$-xylene & $\mathrm{KOH}(0.3)$ & 79 \\
5 & 3.5 & $o$-xylene & $\mathrm{KOH}(0.4)$ & 83 \\
6 & 3.5 & $o$-xylene & $\mathrm{Et}$ N $(0.5)$ & 66 \\
7 & 3.5 & $o$-xylene & $\mathrm{NaOH}(0.5)$ & 89 \\
8 & 3.5 & $o$-xylene & pyridine $(0.5)$ & 50 \\
9 & 3.5 & $\mathrm{NMP}$ & $\mathrm{KOH}(0.5)$ & 78 \\
10 & 3.5 & $\mathrm{H} 2 \mathrm{O}$ & $\mathrm{KOH}(0.5)$ & 40 \\
11 & 3.5 & $\mathrm{MeOH}$ & $\mathrm{KOH}(0.5)$ & 56 \\
12 & 3.5 & $\mathrm{CH}_{3} \mathrm{CN}$ & $\mathrm{KOH}(0.5)$ & 71 \\
\hline
\end{tabular}

Reaction conditions: Benzylalcohol $(1.0 \mathrm{mmol})$, solvent $(5 \mathrm{~mL})$, room temperature, $135 \mathrm{~min}$

${ }^{a}$ Isolated yield 
Table 2. Selectively aerobic oxidation of various benzylalcohols to corresponding aldehydes and ketones.

\begin{tabular}{|c|c|c|c|c|c|}
\hline Entry & Alcohol & Product & Oxidant & Time (min) & Yield $(\%)^{\mathrm{a}}$ \\
\hline 1 & & & Air & 135 & 95 \\
\hline 2 & & & $\mathrm{O}_{2}$ & 20 & 90 \\
\hline 3 & & & $\mathrm{O}_{2}$ & 360 & 81 \\
\hline 4 & & & $\mathrm{O}_{2}$ & 30 & 91 \\
\hline 5 & & & Air & 190 & 89 \\
\hline 6 & & & Air & 90 & 86 \\
\hline 7 & & & Air & 105 & 97 \\
\hline 8 & & & Air & 60 & 90 \\
\hline 9 & & & Air & 40 & 92 \\
\hline 10 & & & Air & 30 & 89 \\
\hline 11 & & & Air & 35 & 93 \\
\hline 12 & & & Air & 30 & 86 \\
\hline 13 & & & $\mathrm{O}_{2}$ & 5 & 94 \\
\hline
\end{tabular}

Reaction conditions: Benzylalcohol $(1.0 \mathrm{mmol}), \mathrm{Co}(\mathrm{II})$-EDANC $(0.2 \mathrm{~g}), \mathrm{KOH}(0.5 \mathrm{mmol}), o$-xylene $(5 \mathrm{~mL})$, room temperature

${ }^{\mathrm{a}}$ Isolated yield

\subsection{Materials and methods for determination of $\mathrm{Co}(I I)$ on $\mathrm{Co}(\mathrm{II})$-EDANC using FAAS}

Co(II)-EDANC $(0.05 \mathrm{~g})$ was added to a mixture of $\mathrm{HCl}: \mathrm{HNO}_{3}(3: 1)(10 \mathrm{~mL})$ and sonicated for $3 \mathrm{~h}$. Then, the mixture was filtered and the total volume of the filtrate made up to about $30 \mathrm{~mL}$ with distilled water. The final solution was aspirated into the flame of the AAS against the blank prepared with EDANC. The Co(II) concentration was obtained using calibration curve prepared with cobalt solution standards.

\subsection{Typical procedure for the oxidation of benzylalcohol}

Benzylalcohol $(0.1 \mathrm{~g}, 1.0 \mathrm{mmol})$ was added to a twonecked flask equipped with a gas bubbling tube containing colloidal of $\mathrm{Co}(\mathrm{II})$-EDANC $(0.2 \mathrm{~g})$ and $\mathrm{KOH}$ $(0.5 \mathrm{mmol})$ in $o$-xylene $(5 \mathrm{~mL})$. Air was bubbled at a rate of $5 \mathrm{~mL} / \mathrm{min}$ into the reaction mixture and the progress of the reaction was followed by thin-layer chromatography (TLC). Upon completion, Co(II)EDANC was separated by filtration and washed with 
Table 3. Successive trials by using recoverable Co(II)EDANC for oxidation of benzylalcohol.

\begin{tabular}{lcc}
\hline Trial & $\begin{array}{c}\text { Catalyst } \\
\text { amount }(\mathrm{g})\end{array}$ & $\begin{array}{c}\text { Yield } \\
(\%)^{\mathrm{a}}\end{array}$ \\
\hline 1 & 0.20 & 95 \\
2 & 0.19 & 95 \\
3 & 0.19 & 93 \\
4 & 0.19 & 93 \\
5 & 0.19 & 93 \\
\hline
\end{tabular}

Reaction conditions: Benzylalcohol (1.0 mmol), Co(II)EDANC $(0.2 \mathrm{~g}), \mathrm{KOH}(0.5 \mathrm{mmol}), o$-xylene $(5 \mathrm{~mL})$, room temperature

${ }^{\mathrm{a}}$ Isolated yield

$\mathrm{CH}_{3} \mathrm{CN}(2 \times 5 \mathrm{~mL})$. The filtrate solvent was evaporated under vacuum and benzylalcohol was purified with column chromatography with $n$-hexane:ethylacetate $(2: 1)$ in $95 \%$ yield.

\section{Results and discussion}

Immobilization of $\mathrm{Co}(\mathrm{II})$ is easily done using its coordination to amine-functionalized cellulose. Such a Co(II)-EDANC catalyst has several advantages over conventional homogeneous catalyst such as possibility of easy workup, recycability and controllability of microenvironments. Distribution of cobalt on the surface afforded an active catalytic system with low loading of $\mathrm{Co}$ (II). The $\mathrm{Co}$ (II) loading on $\mathrm{Co}$ (II)-EDANC catalyst was determined as $1.04 \mathrm{wt} \%$ based on FAAS analysis.

TGA (figure 1) evidenced that $\mathrm{Co}(\mathrm{II})-\mathrm{EDANC}$ has good thermal stability $\left(\mathrm{dec}>235^{\circ} \mathrm{C}\right)$ in air. Also, $\mathrm{Co}$ (II)EDANC was recovered from the reaction decomposed above $235^{\circ} \mathrm{C}$, which showed good thermal stability of the catalyst.

At the onset of the research, we made a conscious effort to develop a heterogeneous bio-catalytic system for selective oxidation of benzylalcohols to the corresponding aldehydes or ketones. During preliminary studies with Co(II)-EDANC, oxidation of benzylalcohol was met with little success in the air atmosphere. Therefore, optimization studies were performed with benzylalcohol as a model substrate and the reaction was screened in the presence of various amounts of $\mathrm{Co}$ (II)EDANC using $\mathrm{KOH}$ in $o$-xylene as a solvent at room temperature. At low Co(II)-EDANC amounts, the reaction gave low yields even in long duration. As Co(II)EDANC amount was increased to $3.5 \mathrm{~mol} \%$, the reaction was carried out more efficiently (table 1, entries 1-3). Addition of a base increased the reaction yield, with inorganic base such as $\mathrm{KOH}$ in $0.5 \mathrm{~mol} \%$ providing the best result (table 1, entries 4-8). Effect of various solvents was investigated on the reaction yields and $o$-xylene was found to be a good media (table 1, entries 9-12).

Efficiency of the catalyst was studied for selective oxidation of various benzylalcohols to the corresponding aldehydes and ketones in the presence of $\mathrm{KOH}$ in $o$-xylene at room temperature (table 2). While, the oxidation of most alcohols was performed in the presence of air, for some of them due to low yields, molecular $\mathrm{O}_{2}$ was used instead of air (table 2, entries 2-4 and 13). The results are very promising and good conversion was obtained in mild reaction conditions.

Recyclability of the Co(II)-EDANC was examined in the oxidation reaction of benzylalcohol. After carrying out the reaction, the reaction mixture was filtered off and Co(II)-EDANC separated as a dark solid, washed with $\mathrm{CH}_{3} \mathrm{CN}(2 \times 5 \mathrm{~mL})$ and reused. Only minor decreases in the reaction yields were observed after five repetitive cycles for the reaction (table 3).

Results of Co(II)-EDANC are compared with Co(II) and $\mathrm{Co}(\mathrm{II})$ impregnated on cellulose with respect to their yields, oxidant, $\mathrm{Co}$ (II) loading, the reaction duration and recyclability of the catalyst. As shown in table 4, Co(II)-EDANC is a recyclable catalyst which performs the reaction with high yield at shorter reaction time in lower loading of $\mathrm{Co}(\mathrm{II})$. This may be attributed

Table 4. Comparasion of results obtained from $\mathrm{Co}(\mathrm{II}), \mathrm{Co}(\mathrm{II})$ impregnated cellulose and Co(II)-EDANC for oxidation of benzylalcohol.

\begin{tabular}{lcccccc}
\hline Entry & Catalyst & Oxidant & $\begin{array}{c}\text { Co(II) } \\
(\mathrm{mol} \%)\end{array}$ & $\begin{array}{c}\text { Time } \\
(\mathrm{min})\end{array}$ & $\begin{array}{c}\text { Yield } \\
(\%)\end{array}$ & Recyclability \\
\hline 1 & Co(II) & Air & 5.0 & 360 & 95 & No \\
2 & Co(II) & $\mathrm{O}_{2}$ & 5.0 & 130 & 95 & No \\
3 & Co(II)-cellulose & Air & 3.5 & 360 & 78 & No \\
4 & Co(II)-cellulose & $\mathrm{O}_{2}$ & 3.5 & 120 & 95 & No \\
5 & Co(II)-EDANC & Air & 3.5 & 135 & 95 & Yes \\
6 & Co(II)-EDANC & $\mathrm{O}_{2}$ & 3.5 & 45 & 95 & Yes \\
\hline
\end{tabular}


to existence of ethylenediamine in the catalyst which as a ligand activates Co(II) for oxidation of alcohols and also improves recyclability of the catalyst. For all the catalysts, oxidation easily performed in the presence of $\mathrm{O}_{2}$ compared to air.

\section{Conclusion}

In conclusion, $\mathrm{Co}(\mathrm{II})$-EDANC as a bio-supportted $\mathrm{Co}$ (II) catalyst was successfully examined in the selective oxidation of various primary and secondary benzylic alcohols to the corresponding aldehydes and ketones in $o$-xylene at room temperature with good yields. Represented systems afforded the selective oxidation of benzylic alcohols in the mild reaction conditions without using any expensive oxidant. The catalyst was easily separated from the reaction mixture with simple filtration and showed good chemical stability, reactivity in the reaction media, and recyclability of the catalyst.

\section{Acknowledgements}

We acknowledge the financial support from the Research Council of Shahid Beheshti University, Iran National Science Foundation (INSF) and Catalyst Center of Excellence (CCE).

\section{References}

1. Haines A H 1985 Methods for the oxidation of organic compounds (New York: Academic Press)

2. Backvall J E 2004 Modern oxidation methods (Weinheim: Wiley-VCH)

3. Zhan B Z and Thompson A 2004 Tetrahedron 602917

4. Baucherel X, Arends I W C E, Ellwood S and Sheldon R A 2003 Org. Process Res. Dev. 7426

5. Minisci F, Recupero F, Rodinò M, Sala M and Schneider A 2003 Org. Process Res. Dev. 7794
6. Parmeggiani C and Cardona F 2012 Green. Chem. 14 547

7. Safavi A, Afsaneh M, Maleki N, Tajabadi F and Farjami E 2007 Electrochem. Commun. 91963

8. Ketchie W C, Murayama M and Davis R J 2007 J. Catal. 250264

9. Raveendran P, Fu J and Wallen S L 2003 J. Am. Chem. Soc. 12513940

10. He F and Zhao D 2005 Environ. Sci. Technol. 393314

11. Raveendran P, Fu J and Wallen S L 2006 Green. Chem. 834

12. Pollmann K, Merroun M, Raff J, Hennig $\mathrm{C}$ and Selenska-Pobell S 2006 Lett. Appl. Microbiol. 4339

13. Lengke M F, Fleet M E and Southam G 2007 Langmuir 238982

14. Klemm D, Heublein B, Fink H P and Bohn A 2005 Angew. Chem. Int. Ed. 443358

15. Reddy K R, Kumar N S, Reddy P S, Sreedhar B and Kantam M L 2006 J. Mol. Catal. A Chem. 25212

16. Cirtiu C M, Dunlop-Briere A F and Moores A 2011 Green. Chem. 13288

17. Youssef H, Lucian A L and Orlando J R 2010 Chem. Rev. 1103479

18. Chen S L, Huang X J and Xu Z K 2011 Cellulose 18 1295

19. Chen S L, Huang X J and Xu Z K 2012 Cellulose 19 1351

20. Keshipour S, Shojaei S and Shaabani A 2013 Cellulose 20973

21. Shaabani A and Rahmati A 2008 Catal. Commun. 9 1692

22. Shaabani A, Farhangi E and Rahmati A 2008 Appl. Catal. A Gen. 33814

23. Shaabani A and Farhangi E 2009 Appl. Catal. A Gen. 371148

24. Shaabani A and Maleki A 2007 Appl. Catal. A 331149

25. Shaabani A, Maleki A, Rad J M and Soleimani E 2007 Chem. Pharm. Bull. 55957

26. Shaabani A, Rahmati A and Badri Z 2008 Catal. Commun. 913

27. Shaabani A, Rezayan A H, Heidary M and Sarvary A 2008 Catal. Commun. 10129

28. Shaabani A, Seyyedhamzeh M, Maleki A and Rezazadeh F 2009 Appl. Catal. A 358146

29. Bondeson D, Mathew A and Oksman K 2006 Cellulose 13171 